\title{
Density Formula for Alkali Silicate Glasses From Annealing to Glass-Processing Temperatures
}

\author{
Leroy W. Tilton
}

\begin{abstract}
An additive formula is given for the computation of specific volumes of molten and compacted alkali silicate binary glasses with modifiers up to 50 -mole percent and from annealing temperatures $\left(400^{\circ}\right.$ or $\left.500^{\circ} \mathrm{C}\right)$ to $1,400^{\circ} \mathrm{C}$. The effective partial volumes, $v_{B}$, for the silica are postulated as

$$
\left(1 / v_{S}\right)=2.198+r_{\mathrm{m}} C_{S}(1723-t),
$$

where $r_{m}$ is the mole fraction of nonsilica and $C_{S}$ is a constant to be evaluated from glassdensity data. This is based on the idea that silica networks can contract in volume as temperatures are lowered provided, and in proportion as, modifier ions are present in the glass. The effective partial volumes of $\mathrm{R}_{2} \mathrm{O}$, the nonsilica, are assumed as linear functions of temperature but not of the fraction of silica present.

Computed and observed densities agree within approximately 1 percent. The effective volumes of nonsilica are somewhat smaller than published estimates for the oxides themselves, as should be expected because of interpenetrations.
\end{abstract}

Previous formulas for the computation of densities of glasses have related principally to variations in composition. The formula proposed by Stevels [1] ${ }^{1}$ is based on ideas of structure and has very few constants. It assumes for restricted ranges in composition that volume is independent of the nature of the cation. As modified by Stanworth [2] it shows that volume is dependent on the size of the cations, the glass volumes being larger as cation radii are larger.

The additive formula proposed by Huggins [3] has many constants, and it is notably successful. That work is of considerable interest to anyone interested in structure because Huggins finds that the addition of every cation oxide molecule linearly increases the volume of a glass per oxygen atom, regardless of previous additions. However, at least for $\mathrm{R}_{2} \mathrm{O}$ silicate glasses, it can be shown that the linearity is not dependent on the referral to oxygen, and his corresponding partial volumes of nonsilica (not referred to oxygen) also are found to be linear if plotted against mole fraction of the added oxide. ${ }^{2}$

The Huggins formula is of further interest because the partial volumes used for silica are almost identical in the presence of various kinds of nonsilicas and are so treated except for the presence of a few elements, notably boron. Most interesting of all in connection with the present paper, his partial molar volumes (P. M. V.) attributable to silica ${ }^{3}$ decrease as larger amounts of modifier are added. The Huggins stepwise procedure in dealing with the silica component is roughly equivalent to the procedure mentioned by LeChatelier [13], namely an arbitrary dual

\footnotetext{
1 Figures in brackets indicate the literature references at the end of this paper. 2 Although the Huggins partial volumes for silica (whether or not referred to oxygen) are more nearly representable by a smooth curve when plotted against oxygen) are more nearly representable by a smooth curve when plotted against
mole fraction of silica than against the Si to $O$ ratio (used by Huggins), their mole fraction of silica than agginst the $\mathrm{Si}$ to $\mathrm{O}$ ratio (used by Huggins), their
better representation by segments of straight lines can still be shown. The better representation by segments of straight lines can still be shown. The
Huggins special points of intersection correspond to compositions where there Huggins special points of intersection correspond to compositions wher
are integral numbers of cations per cage according to vitron theory $[5,6]$. are integral numbers of cations per cage according to vitron theory $[5,6]$.
8 Computable from Huggins' table 1 as P. M. V. $=2 b_{\text {si }}+c_{8 \mathrm{i}}$. See White [8] p. 24 to 28 .
}

calculation of the volumes attributable to silica, partly from the density of silica glass and partly from that of the crystalline silica phases. Biltz and Weibke [14] proceeded in a slightly less arbitrary manner and calculated volumes of "average mols" of glass by the additive rule after taking into account the specific volumes of certain crystal phases that could be derived from the equilibrium diagrams and therefore might be presumed to exist in the liquid silicates.

The procedures mentioned are certainly not inconsistent with a conclusion from data on annealing [4] that the nonsilica particles, chiefly in proportion to their mere number, seem to govern the extent of partial collapse of the silica framework. A decrease in the bond angle $\mathrm{Si}-\mathrm{O}-\mathrm{Si}$, where the tetrahedra are connected, was suggested.

The object of this paper is to see if the additivity of volumes in alkali silicate glasses at high temperatures is compatible with the idea of a silica that is continuously variable in density as a function of both temperature and modifier content. The following considerations also are relevant to the development of the proposed formula:

(1) A bond-angle theory of annealing [4];

(2) Known linear variations of densities of glasses at equilibrium in the annealing ranges [4];

(3) Shermer's [7] curves for densities of molten glasses as functions of composition, showing (qualitatively ${ }^{4}$ ) the marked increases in expansivities as cation is added to silica;

(4) White's [8] finding that densities of molten alkali silicates vary nearly linearly with temperature over a $400^{\circ}$ C range;

(5) White's report that the silicon-oxygen structure in molten silicates is not only similar to that in vitreous silica but is independent of the kind of cations present; and

(6) White's report that the partial molar volumes of silica are identical for the alkali silicates and decrease as cation is added.

- The slopes of Shermer's density curves from room temperature to $400^{\circ} \mathrm{C}$ are about $1 / 3$ as steep as is indicated by the coefficients in his table 1 . 
The basis for development is the well-known additivity of volumes, so that the specific volume of a glass may be written:

$$
V_{g}=\frac{1}{d}=s_{w} v_{S}+r_{w} v_{R},
$$

where $v_{S}$ and $v_{R}$ are effective partial specific volumes attributable to the silica network and the nonsilica modifier, respectively, and $s_{w}$ and $r_{w}$ are the respective weight fractions.

For each modifier oxide, the effective density is assumed as a linear function of temperature

$$
\left(1 / v_{R}\right)=A_{R}+B_{R}(1,400-t),
$$

where $1,400^{\circ} \mathrm{C}$ is used because it will be desired later to compare directly the empirically determined $A$ constants with White's estimates at $1,400^{\circ} \mathrm{C}$.

The problem, then, is to find a suitable expression for $v_{S}$, the effective volume of the silica. As a first approximation one might use $v_{S}$ as a constant independent of temperature and modifier concentration. If this be done then it is found necessary to express each of three values of $v_{R}$ not only as a function of temperature but of modifier content. It is simpler to assume that only silica volume, $v_{S}$, is a function of modifier content.

It is desired that $1 / v_{S}$ have the value $2.198 \mathrm{~g} / \mathrm{cm}^{3}$ at $1,723^{\circ} \mathrm{C}$, the melting point, and at all temperatures in the absence of modifier oxides; also that it decrease monotonically with temperature for a given degree of modification, and increase with modification at constant temperatures other than $1,723^{\circ} \mathrm{C}$.

Hence it is postulated that in the presence of any alkali modifier

$$
\left(1 / v_{S}\right)=2.198+r_{m} C_{S}(1,723-t),
$$

where $r_{m}$ is the mole fraction of nonsilica and $C_{S}$ is a constant to be evaluated from the glass-density data.

Other procedures can, of course, be followed in seeking to express as a continuous function the changes with temperature and modification that seem necessary for successfully computing glass densities. It seems preferable to follow precedent in attributing the changes mainly to the silica component $[3,13,14]$, as mentioned above.

The assumption of eq (2) leads to much lower and more reasonable temperature coefficients, $B$, for $v_{R}$ than would otherwise be found necessary in eq (3). Incidentally, the form of eq (2) accords with ideas previously expressed [4] concerning the nature of the structural rearrangements and volume changes in silicate glasses in their annealing ranges, namely that the silicon-oxygen bond is temperature sensitive (undergoes more electron cloud distortion, and becomes more angularly directed) in proportion as nonsilica particles (metal ions) are present. The operation of formula (1) together with the auxiliary eq (2) and (3), depends importantly on the use of the factor $r_{m}$ as included in eq (2) for evaluating the effective partial specific volume, $v_{S}$ of the silica.
In eq (2) the constant $C_{S}$ is the slope or the temperature-contraction rate, $-\Delta d / \Delta t$, for a network of vitreous silica collapsed as fully as can be accomplished by the presence of alkali ions. In other words, the slopes of a family of curves of the effective partial densities of silica itself (but permeated with alkali modifiers) versus temperature are expressed by $-r_{m} C_{S}$ and the partial derivative of such slopes with respect to $r_{m}$ is $-C_{S}$.

From experiments [4] on volume changes of complex glasses in their annealing ranges only, and thus for an average of numerous types of modifiers, a value of $C_{S}=+0.00057$ might be expected. ${ }^{5}$ Actually, for use in eq (2) for computing densities of alkali silicates in the annealing range and up to $1,400^{\circ} \mathrm{C}$, a still lower value of +0.00040 is now empirically recommended (after several trials with larger slopes ${ }^{6}$ ).

The constants $A$ and $B$ were successively determined from the glass densities after assuming various values of $C_{S}$. A value $C_{S}=0.00040$ was found to give the best fitting curves when residuals were averaged for all three modifiers at four temperatures, namely annealing, $900^{\circ}, 1,150^{\circ}$, and $1,400^{\circ} \mathrm{C}$.

The "observed" values for molten glasses are computed ${ }^{7}$ from those that White [8] tabulated at $1,400^{\circ} \mathrm{C}$ with coefficients for other temperatures from near $1,000^{\circ}$ to $1,500^{\circ} \mathrm{C}$. White shows that his results at $1,400^{\circ} \mathrm{C}$ are in fair agreement with those by Heidtkamp and Endell [9] and those by Shartsis, Spinner, and Capps [10]. The "observed" values for compacted glasses at room temperature and at their critical temperatures are based on the densities published by Young, Glaze, Faick, and Finn [11] and on thermal coefficients tabulated by Shermer [7] and by Schmid, Finn, and Young [12].

The best effective densities, $1 / v_{R}$, for use in eq (1) are

$$
\begin{aligned}
1 / v_{L i} & =1.700+0.000332(1,400-t), \\
1 / v_{N a} & =2.117+0.000416(1,400-t), \\
1 / v_{K} & =2.066+0.000428(1,400-t) .
\end{aligned}
$$

This implies that the effective densities of the oxides in the silicates at $1,400^{\circ} \mathrm{C}$ are $1.70,2.12$, and 2.07 which are 10,12 , and 14 percent higher than the densities computable for the oxides themselves from volume estimates as given by White [8] for $\mathrm{Li}_{2} \mathrm{O}$, $\mathrm{Na}_{2} \mathrm{O}$, and $\mathrm{K}_{2} \mathrm{O}$, respectively. These percentages can be considered to some extent indicative of inter-

\footnotetext{
${ }^{5}$ From eq $(1)$ of the reference cited $(\Delta n / \Delta t)=-0.00010 r_{m}$ and from the NewtonLaplace relation between refractive index and density, namely $\left(n^{2}-1\right)=d C$, one finds by differentiation that $(\Delta d / \Delta n)=1 / 0.176$. Hence $(\Delta d / \Delta t)=-0.00057 r_{m}$ for a silica network stabilized by the presence of various metallic ions, and $C_{S}=$ a silica network stabilized by the presence of various metallic ions, and $C_{S}=$ $18.7 \mathrm{~cm}^{3}$ for stabilized silica network at absolute zero, as compared with $27.3 \mathrm{~cm}^{3}$ $18.7 \mathrm{~cm}^{3}$ for stabilized silica network at absolute zero, as compared with $27.3 \mathrm{~cm}$ -
for metastable silica glass. This would be silica with 39 -percent voids, even if one may consider oxygen and silicon as solid spheres with radii, 1.31 and $0.29 \mathrm{~A}$, respectively. Such a condition is then not unreasonable because it is intermediate between the known conditions for densest packing of spheres (26-\% voids) and for most open packing (48-\% voids).

${ }_{6}^{6}$ It can be shown that the higher value of $C_{S}=0.00057$ can be used if a threshold value of $r_{m}=0.12$ is assumed for the beginning of configurational thermal expansion. See White $[8]$ p. 106.

7 The computations are in several cases extrapolations from White's data to
} $900^{\circ} \mathrm{C}$. 
Table 1. Comparison of computed and observed densities

\begin{tabular}{|c|c|c|c|c|c|c|c|c|c|c|c|c|}
\hline \multirow{2}{*}{$\begin{array}{c}\text { Mole } \\
\text { per- } \\
\text { cent } \\
\mathrm{R}_{2} \mathrm{O}\end{array}$} & \multicolumn{3}{|c|}{ Annealing temperature } & \multicolumn{3}{|c|}{$900^{\circ} \mathrm{C}$} & \multicolumn{3}{|c|}{$1,150^{\circ} \mathrm{C}$} & \multicolumn{3}{|c|}{$1,400^{\circ} \mathrm{C}$} \\
\hline & Computed & Observed & $(c-0) \times 10^{3}$ & Computed & Observed & $(c-0) \times 10^{3}$ & Computed & Observed & $(c-0) \times 10^{3}$ & Computed & Observed & $(c-0) \times 10^{3}$ \\
\hline \multicolumn{13}{|c|}{$\mathrm{Li}_{2} \mathrm{O} \cdot \mathrm{S}_{\mathrm{i}} \mathrm{O}_{2}$} \\
\hline $\begin{array}{l}10 \\
20 \\
30 \\
40 \\
50 \\
60\end{array}$ & $\begin{array}{l}\text { 2. } 232 \\
\text { 2. } 263 \\
\text { 2. } 283 \\
\text { 2. } 299 \\
\text { 2. } 298 \\
----\end{array}$ & $\begin{array}{c}\text { 2. } 239 \\
\text { 2. } 275 \\
\text { 2. } 298 \\
\text { 2. } 313 \\
---- \\
----\end{array}$ & $\begin{array}{r}-7 \\
-12 \\
-15 \\
-14 \\
---- \\
----\end{array}$ & $\begin{array}{l}\text { 2. } 213 \\
\text { 2. } 215 \\
\text { 2. } 208 \\
\text { 2. } 197 \\
\text { 2. } 172 \\
\text { 2. } 137\end{array}$ & $\begin{array}{l}\text { 2. } 206 \\
\text { 2. } 216 \\
\text { 2. } 194 \\
\text { 2. } 167 \\
\text { 2. } 108\end{array}$ & $\begin{array}{r}+ \\
+9 \\
-8 \\
+3 \\
+5 \\
+29\end{array}$ & $\begin{array}{l}\text { 2. } 183 \\
\text { 2. } 181 \\
\text { 2. } 164 \\
\text { 2. } 138 \\
\text { 2. } 104 \\
\text { 2. } 062\end{array}$ & $\begin{array}{ll}\text { 2. } & 187 \\
\text { 2. } & 177 \\
\text { 2. } & 146 \\
\text { 2. } & 111 \\
\text { 2. } & 044\end{array}$ & $\begin{array}{r}-- \\
-6 \\
-13 \\
-8 \\
-7 \\
+18\end{array}$ & $\begin{array}{l}\text { 2. } 180 \\
2.152 \\
2.120 \\
\text { 2. } 083 \\
\text { 2. } 040 \\
\text { 1. } 988\end{array}$ & $\begin{array}{l}\text { 2. } 169 \\
\text { 2. } 138 \\
\text { 2. } 098 \\
\text { 2. } 055 \\
\text { 1. } 980\end{array}$ & $\begin{array}{r}-17 \\
-18 \\
-15 \\
-15 \\
+8\end{array}$ \\
\hline \multicolumn{13}{|c|}{$\mathrm{Na}_{2} \mathrm{O} \cdot \mathrm{S}_{\mathrm{i}} \mathrm{O}_{2}$} \\
\hline $\begin{array}{l}10 \\
20 \\
30 \\
40 \\
50 \\
60\end{array}$ & $\begin{array}{l}\text { 2. } 272 \\
\text { 2. } 342 \\
\text { 2. } 404 \\
\text { 2. } 457 \\
\text { 2. } 496 \\
\text { 2. } 524\end{array}$ & $\begin{array}{l}\text { 2. } 276 \\
\text { 2. } 354 \\
2.420 \\
\text { 2. } 468 \\
\text { 2. } 514\end{array}$ & $\begin{array}{r}-4 \\
-12 \\
-16 \\
-11 \\
-18 \\
--\end{array}$ & $\begin{array}{l}\text { 2. } 242 \\
\text { 2. } 278 \\
\text { 2. } 306 \\
\text { 2. } 331 \\
\text { 2. } 344 \\
\text { 2. } 352\end{array}$ & $\begin{array}{l}\text { 2. } 271 \\
\text { 2. } 308 \\
\text { 2. } 322 \\
\text { 2. } 336 \\
\text { 2. } 323\end{array}$ & $\begin{array}{r}+7 \\
+2 \\
+9 \\
+8 \\
+29\end{array}$ & $\begin{array}{l}\text { 2. } 223 \\
\text { 2. } 241 \\
\text { 2. } 252 \\
\text { 2. } 263 \\
\text { 2. } 267 \\
\text { 2. } 264\end{array}$ & $\begin{array}{l}\text { 2. } 247 \\
\text { 2. } 259 \\
\text { 2. } 261 \\
\text { 2. } 264 \\
\text { 2. } 243\end{array}$ & $\begin{array}{r}--\overline{-} \\
-7 \\
+2 \\
+3 \\
+21\end{array}$ & $\begin{array}{l}\text { 2. } 202 \\
\text { 2. } 202 \\
\text { 2. } 200 \\
\text { 2. } 194 \\
\text { 2. } 187 \\
\text { 2. } 176\end{array}$ & $\begin{array}{l}\text { 2. } 210 \\
\text { 2. } 222 \\
\text { 2. } 210 \\
\text { 2. } 201 \\
\text { 2. } 192 \\
\text { 2. } 163\end{array}$ & $\begin{array}{r}-8 \\
-20 \\
-10 \\
-7 \\
-5 \\
+13\end{array}$ \\
\hline \multicolumn{13}{|c|}{$\mathrm{K}_{2} \mathrm{O} \cdot \mathrm{S}_{\mathrm{i}} \mathrm{O}_{2}$} \\
\hline $\begin{array}{l}10 \\
20 \\
30 \\
40 \\
50\end{array}$ & $\begin{array}{l}\text { 2. } 283 \\
\text { 2. } 352 \\
\text { 2. } 413 \\
\text { 2. } 457 \\
\text { 2. } 491\end{array}$ & $\begin{array}{c}\text { 2. } 282 \\
\text { 2. } 355 \\
\text { 2. } 405 \\
-\ldots-- \\
-\ldots-\end{array}$ & $\begin{array}{r}+1 \\
-3 \\
+8 \\
--- \\
---\end{array}$ & $\begin{array}{l}\text { 2. } 242 \\
\text { 2. } 271 \\
\text { 2. } 293 \\
\text { 2. } 307 \\
\text { 2. } 313\end{array}$ & $\begin{array}{l}\text { 2. } 216 \\
\text { 2. } 262 \\
\text { 2. } 284 \\
\text { 2. } 290\end{array}$ & $\begin{array}{r}+26 \\
+9 \\
+9 \\
+17 \\
----\end{array}$ & $\begin{array}{l}\text { 2. } 217 \\
\text { 2. } 225 \\
\text { 2. } 229 \\
\text { 2. } 230 \\
\text { 2. } 226\end{array}$ & $\begin{array}{l}\text { 2. } 216 \\
\text { 2. } 223 \\
\text { 2. } 220 \\
\text { 2. } 213\end{array}$ & $\begin{array}{r}+1 \\
+2 \\
+9 \\
+17 \\
----\end{array}$ & $\begin{array}{l}\text { 2. } 191 \\
\text { 2. } 179 \\
\text { 2. } 166 \\
\text { 2. } 151 \\
\text { 2. } 140\end{array}$ & $\begin{array}{l}\text { 2. } 216 \\
\text { 2. } 184 \\
\text { 2. } 156 \\
\text { 2. } 136 \\
.\end{array}$ & $\begin{array}{r}-25 \\
-5 \\
+10 \\
+15 \\
+---\end{array}$ \\
\hline
\end{tabular}

penetration of the silica network cavities with these modifiers. Correspondingly, in eq (3) the temperature coefficients of density are 6,8 , and 16 percent higher than those computable from differencing White's estimates of oxide volumes at room temperature and at $1,400^{\circ} \mathrm{C}$.

The complete formula yields densities of which two-thirds agree with observed densities within one-half percent over the range $1,400^{\circ}$ to $400^{\circ}$ or $500^{\circ} \mathrm{C}$ for both molten glasses and those in the annealing ranges, as shown in table 1.

From the residuals, c-o, in table 1 it is evident that the proposed density formula fits the data fairly well over the long range in temperature. This is illustrated in figures 1, 2, and 3 where, for the three systems, rough comparisons are also made with data by observers other than White. The slopes in figures 1, 2, and 3 show how regularly the expansivities increase as modifiers are added. The approximate constancy of expansivity from annealing temperatures to those of molten glasses accords with the idea that glass structure does not change fundamentally within these temperature ranges.

When more numerous and more precise data become available it may be found, for glasses nearly saturated with modifiers, that observed densities in the annealing ranges differ systematically from those computed by this formula as adjusted to fit densities not only for annealing ranges but for molten glasses also. This expectation is based on the postulated characteristics of vitrons. Saturated cages of vitrons $[5,6]$ cannot be expected to respond as freely to bond-angle contraction during cooling as is assumed for unsaturated cages considered in this simple formula. The resulting stresses that develop on further cooling may eventually cause some breaking of bonds so that the delayed bondangle contraction can then proceed. Some indication of such systematic tendencies is shown by the predominantly positive residuals in the $900^{\circ}$ column of table 1, and the almost exclusively negative residuals in the annealing-temperature column.

As modifiers are added, there is in these residuals another and more definite systematic trend. The computed densities must be regarded as averages over the composition ranges because the formula has no terms relating to degree of saturation. The computed densities are too low at low modifier content and become too high at higher percentages of nonsilica particularly for molten glasses at highest temperatures listed. This is clearly indicated in figure 4.

It will be noticed that maximum excess of observed densities tends to shift toward higher percentage modifications in the order $\mathrm{K}_{2} \mathrm{O}, \mathrm{Na}_{2} \mathrm{O}, \mathrm{Li}_{2} \mathrm{O}$. Indeed the maxima for $\mathrm{K}_{2} \mathrm{O}$ and $\mathrm{Na}_{2} \mathrm{O}$ occur at lower percentages than 16.7 and 23.1, respectively, at which it has been suggested that complete inclosure of oxygen in the dodecahedral cages should cease and the breaking of oxygen bridges should begin. It happens also, that the excesses change to deficiencies not far from the percentages 28.6, 37.5, and 50 that have been identified with complete saturation of the cages. 


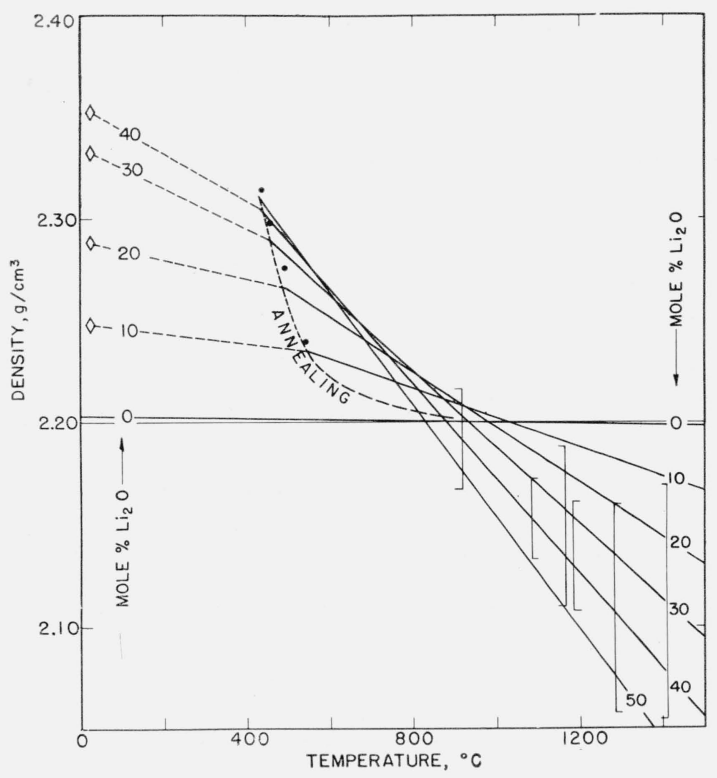

FIGURE 1. Densities of lithia silicate glasses as functions of temperature.

Full lines represent computations by the proposed formula. Diamonds represent observed values at room temperature by Young et al. [11]. Dotted lines lead to densities computed by formula at the annealing temperatures. Filled circles represent densities computed for annealing temperatures by use of room temperature densities and expansivities as measured by Schmid et al. [12] and by Shermer [7]. The total ranges in White's [8] observed values, for 20- to 50 -mole percent of $\mathrm{Li}_{2} \mathrm{O}$, are indicated by brackets open to the left. The ranges in observed data by Shartsis et al. [10], 20-odd to 40-odd mole percent of $\mathrm{Li}_{2} \mathrm{O}$, are in observed data by Shartsis et al. [10], 20-odd to 40-odd mole percent of $\mathrm{Li}_{2} \mathrm{O}$, are
shown by right-face brackets. Shermer's similar diagram from observed data suggests a minimum spread in crossings of lines just below $800^{\circ} \mathrm{C}$.

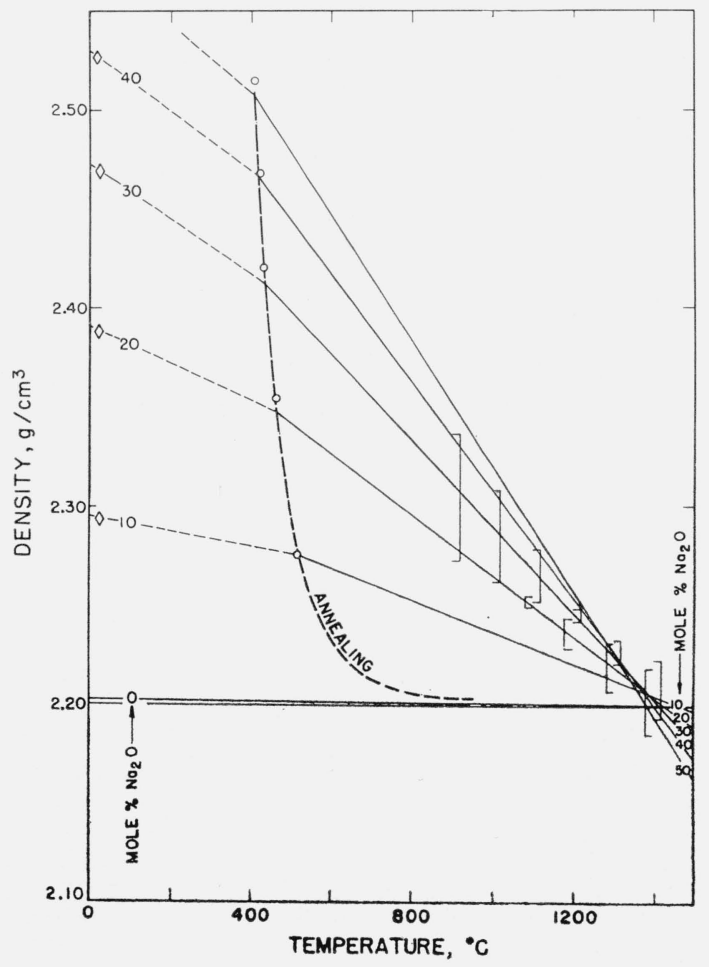

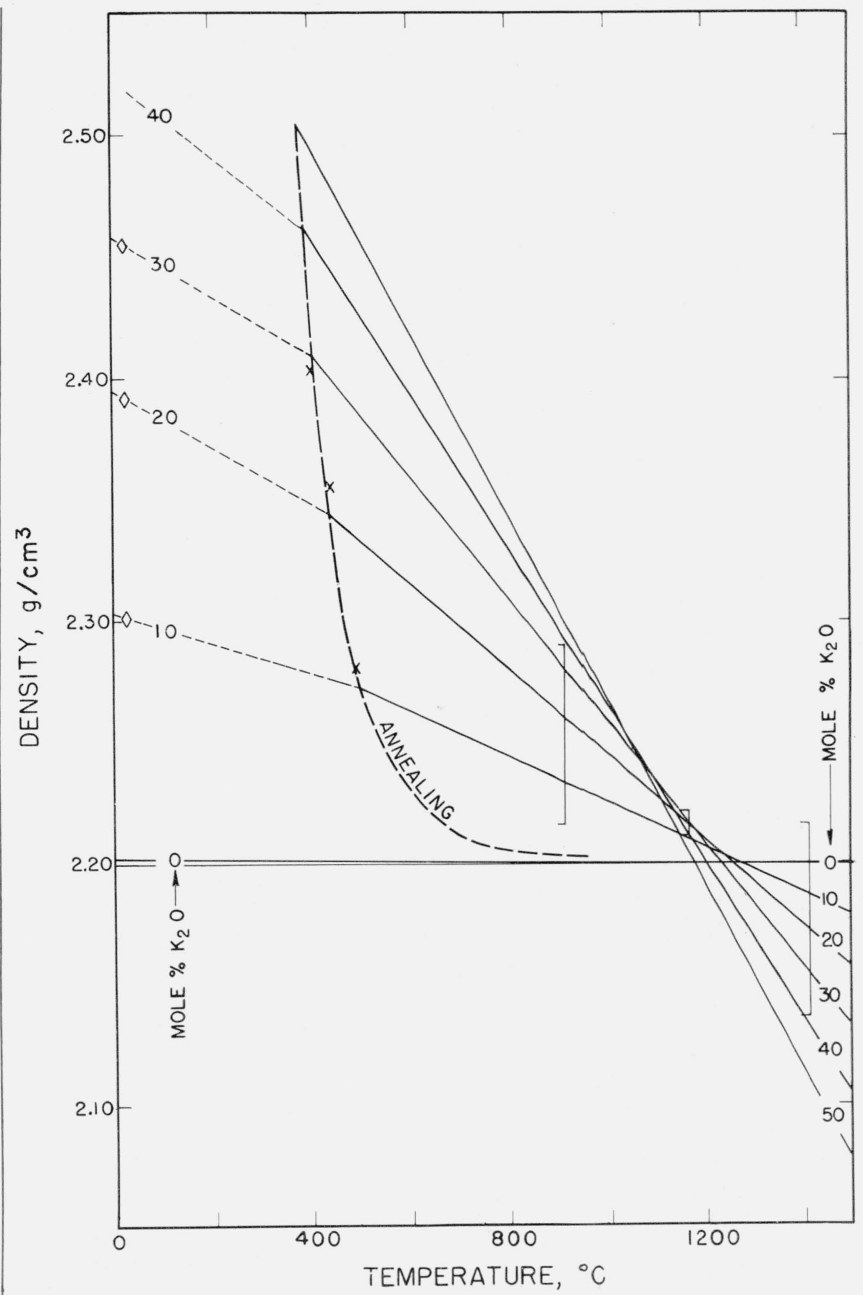

Figure 3. Densities of potash silicate glasses as functions of temperature.

The brackets indicate data by White [8] for 10- to 40-mole percent of $\mathrm{K}_{2} \mathrm{O}$ Shermer's diagram suggests minimum spread in crossings near $1,100^{\circ} \mathrm{C}$.

Figure 2. Densities of soda silicate glasses as functions of temperature.

The left-face brackets represent data by White [8] for 20 - to 50 -mole percent of $\mathrm{Na}: \mathrm{O}$. The right-face brackets represent data by Heidtkamp and Endell [9] for 20 - to 50 -mole percent of $\mathrm{Nas} \mathrm{O}$ (except at $1,100^{\circ} \mathrm{C}$ where their modifier range is only 30 to 50 percent). Shermer's [7] diagram suggests minimum spread in crossings just below $1,350^{\circ} \mathrm{C}$. 


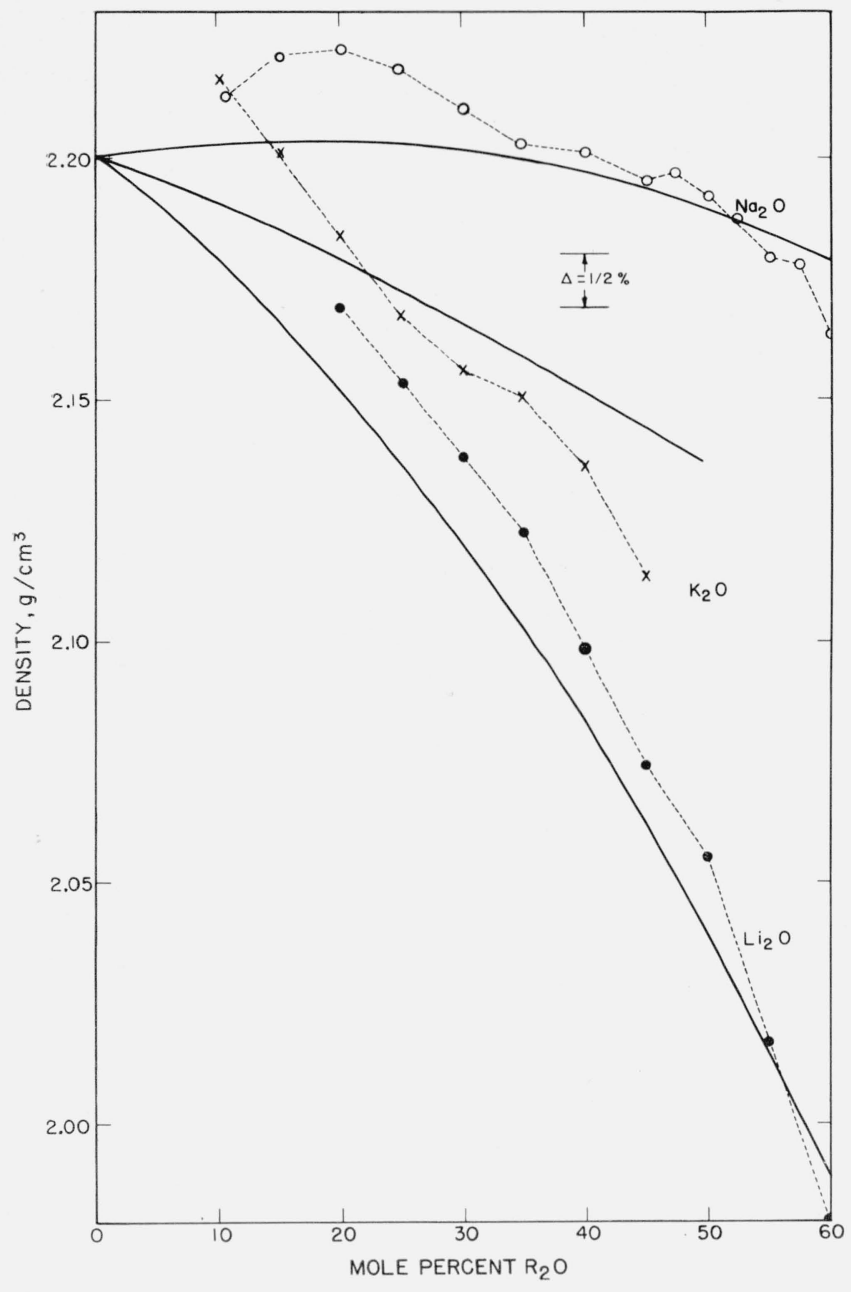

FIGURE 4. Comparison of computed and observed densities of binary silicate glasses at $1,400^{\circ} \mathrm{C}$.

Full lines represent computed densities. Dotted lines connect densities observed by White [8]. Since the simple formula has no terms relating to satura tion of the cavities, it is to be expected that (with an average adjustment) excess of observed values should be found principally at nonsilica contents below 28.6$37.5-$, and 50 -mole percent for $\mathrm{K}_{2} \mathrm{O}, \mathrm{Na}_{2} \mathrm{O}$, and $\mathrm{Li}_{2} \mathrm{O}$, respectively, because these are the percentages tentatively assigned for complete saturation according to vitron theory $[5,6]$.

Washington, April 10, 1958.
In addition to the results listed in table 1, data for two ternary glasses investigated by White were used. Each contained 60-mole percent of $\mathrm{SiO}_{2}$ and 20 percent of $\mathrm{Li}_{2} \mathrm{O}$. For one with 20 percent of $\mathrm{Na}_{2} \mathrm{O}$ the computed and observed densities at $1,400^{\circ} \mathrm{C}$ were 2.147 and 2.155 ; similarly for one with 20 percent of $\mathrm{K}_{2} \mathrm{O}, 2.123$, and 2.126 , respectively.

In resumé the following points are emphasized:

(1) A simple additive formula [1], if written in accord with an effective partial value of silica as postulated by eq (2), represents the data on alkali silicates approximately as well as they are known. The systematic trends in the residuals seem qualitatively in accord with expectations from vitron theory.

(2) The use of a factor $r_{m}$ in eq (2) is analogous to Huggins' [3] use for silica of a parameter variable with modifier concentration. The need for such a procedure was indirectly implied by White [8] and by Callow [15]. (See considerations as above listed.)

(3) The empirically determined constant, $C_{\boldsymbol{S}}$, for silica in eq (2) is reasonable in that it is interpretable as a temperature collapse rate for silica network that extrapolates to reasonable volumes at $0^{\circ} \mathrm{K}$.

(4) The empirically determined constants for nonsilica in eq (3) are reasonable in that they approximate the densities of the oxides and their temperature coefficients within 10 or 15 percent of estimated values.

It would appear from the analysis in this paper that to a first approximation the sensitive-bond-angle concept for silica with alkali modifiers is semiquantitatively compatible with our knowledge of the densities of alklali silicate glasses.

\section{References}

[1] J. M. Stevels, J. Soc. Glass Technol, 30, 31 (1946)

[2] J. E. Stanworth, J. Soc. Glass Technol. 30, 54 (1946).

[3] M. L. Huggins, J. Opt. Soc. Am. 30, 420 (1940).

[4] L. W. Tilton, J. Soc. Glass Technol. 40, 338T (1956).

[5] L. W. Tilton, J. Research NBS 59, 139 (1957) RP2782

[6] L. W. Tilton, J. Research NBS 60, 351 (1958) RP2854.

[7] H. F. Shermer, J. Research NBS 5\%, 97 (1956) RP2698.

[8] J. L. White (Ph. D. Thesis, Univ. of California 1955)

[9] G. Heidtkamp and K. Endell, Glastech. Ber. 14, 89 (1936).

[10] L. Shartsis, S. Spinner, and W. Capps, J. Am. Ceram. Soc. 35, 155 (1952).

[11] J. C. Young, F. W. Glaze, C. A. Faick, and A. N. Finn J. Research NBS 22, 453 (1939) RP1197.

[12] B. C. Schmid, A. N. Finn, J. C. Young, J. Research NBS 12, 421 (1934) RP667.

[13] H. LeChatelier, Kieselsaüre und Silikate, p. 240 (Leipzig, 1920).

[14] W. Biltz and F. Weibke, Z. anorg. allgem. Chem. 203, 345 (1932).

[15] R. W. Callow, J. Soc. Glass Technol. 36, 137 (1952). 